\title{
LA POLÍTICA EDUCATIVA COLONIAL EN CUBA Y LA INSURRECCIÓN DE LOS CATEDRÁTICOS DE INSTITUTO EN LA SEGUNDA MITAD DEL SIGLO XIX'
}

COLONIAL EDUCATIONAL POLICY IN CUBA AND THE INSURRECTION OF INSTITUTE PROFESSORS IN THE SECOND

HALF OF THE XIX CENTURY

\author{
José Antonio Cañizares Márquez \\ Universidad Complutense de Madrid \\ ORCID: 0000-0002-8876-426I \\ jacmarquez@ucm.es
}

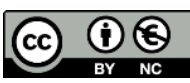

\section{Resumen}

En este artículo se presenta un estudio de la política educativa colonial en Cuba durante la segunda mitad del siglo XIX, deteniendo su atención sobre el protagonismo de los catedráticos de instituto en el proceso independentista. La Constitución de 1837 establecía leyes especiales para las provincias de Ultramar. En la enseñanza, las promesas formales de asimilación con la península jamás se llevaron a la práctica, aunque si se aplicaron en los demás ramos de la administración. En ese contexto se inició la ruptura con la metrópoli y comenzó a formarse la conciencia nacional cubana. En la etapa de la guerra de los Diez Años (1868-1878) el sesenta y cinco por ciento de los catedráticos de instituto fueron acusados por delitos de infidencia, separados de sus cátedras y algunos ejecutados por colaborar con los insurrectos. También se suprimieron numerosos establecimientos de enseñanza porque, según las autoridades españolas, eran fueros de insurrección donde se fomentaban ideas independentistas. La insurrección de 1868 en Cuba fue interpretada, sobre todo por parte de la élite liberal española, como una guerra civil, pero en realidad fue una revolución burguesa de liberación nacional.

Palabras clave: Cuba; Política colonial; Educación; Catedráticos; Insurrección; Guerra.

\section{Abstract}

This article presents a study of colonial educational policy in Cuba during the second half of the 19th century, focusing on the role of high school professors in the independence process. The Constitution of 1837 established special laws for the overseas provinces. In education, the formal promises of assimilation with the peninsula were never carried out, although they were applied in other branches of the administration. In this context, the break with the metropolis began and the Cuban national conscience began to form as well. In the stage of the Ten Years' War (1868-1878), sixty-five percent of the institute professors were accused of crimes of infidelity, separated from their chairs and some executed for collaborating with the insurgents. Also, numerous educational establishments were suppressed because, according to the Spanish authorities, they were places of insurrection where

${ }^{1}$ Recibido/Received: |4/|2/202|

Aceptado/Accepted: 21/0I/2022

SHJ, 2022, 2(I), pp. 46-68. ISSN: 2792-3967

46 
independence ideas were promoted. The 1868 insurrection in Cuba was interpreted, especially by the Spanish liberal elite, as a civil war, but in reality, it was a bourgeois revolution of national liberation.

Keywords: Cuba; Colonial Policy; Education; Professors; Insurrection; War.

\section{| Introducción |}

El objetivo de este trabajo es doble. Por un lado, mostrar la relevancia de los catedráticos de institutos públicos como colaboradores de la causa independentista en Cuba durante la Guerra Grande (1868-1878). Por otro, exponer que, en esa época, el establecimiento, reforma y supresión de institutos de segunda enseñanza fue debido a motivaciones políticas. El texto también considera aspectos fundamentales de la política colonial de segunda enseñanza en Cuba en la segunda mitad del siglo XIX: los estudios, los establecimientos de enseñanza y el gobierno y administración de la instrucción pública. El propósito e interés de esta investigación se centra en describir y analizar los orígenes, las causas y consecuencias que provocaron las políticas educativas en Cuba y su influencia como factor de nacionalización, así como el protagonismo de los catedráticos en la insurrección.

La hipótesis central de esta investigación se apoya en el supuesto de que, desde 1868, el papel de los catedráticos de instituto en el proceso independentista cubano no fue un hecho residual, sino que, tanto por el número de catedráticos implicados en el proceso como por la respuesta del gobierno español a esa rebelión, el protagonismo de los catedráticos fue muy relevante en el acontecer político de la colonia. Teniendo en cuenta la extraordinaria importancia de la colonia de Cuba en el contexto de la política imperial española, la hipótesis plantea que el papel desempeñado por los catedráticos en el proceso independentista es un hecho digno de interés científico que debe ser analizado con perspectiva histórica. De hecho, hemos cuantificado en un 65 por ciento el porcentaje de catedráticos declarados infidentes por participar en la insurrección de 1868. La investigación se ha detenido es aspectos tales como su procedencia (si españoles o criollos), su formación académica, la variación de los procesos independentistas en los institutos de las distintas regiones geográficas y cuáles se vieron más afectadas por los delitos de infidencia.

De modo especial se han tenido en cuenta para la realización de este trabajo las fuentes primarias, ya que el estudio de la participación política de los catedráticos en el proceso independentista ha quedado hasta la fecha prácticamente inexplorado, tan solo abordado a través de unas pocas líneas en algunas monografías de historia de la educación en Cuba, como la de (Sosa Rodríguez y Penabad Félix, 2010). La información bibliográfica es prácticamente inexistente, por lo que hay que recurrir a los expedientes disponibles en los fondos de los archivos nacionales de Cuba y España, la colección de manuscritos de la sala cubana de la Biblioteca Nacional José Martí, la Biblioteca del Instituto de Historia de Cuba y la Biblioteca Nacional de España. De las fuentes impresas, informes y memorias hay que destacar una fuente muy útil para nuestra investigación: la Gaceta de SHJ, 2022, 2(I), pp. 46-68. ISSN: 2792-3967 
la Habana², periódico oficial del Gobierno, donde se publicaban los nombres de los acusados de delitos de infidencia a los que se les embargaba sus bienes. A ello hay que añadir la bibliografía sobre Cuba, reciente y contemporánea, del período estudiado.

He utilizado metodologías transversales, comparativas e interdisciplinares para analizar la política educativa de segunda enseñanza en Cuba como reflejo de la política colonial, considerando las aportaciones de la sociología histórica de tradición weberiana ${ }^{3}$ y aplicando técnicas de carácter cualitativo y cuantitativo. Algunos de los registros sobre la participación de los catedráticos en el proceso independentista se han obtenido de modo indirecto, ya que algunos expedientes no están localizables, pero se ha podido atestiguar su participación en el proceso cuando aparecía alguna reseña de embargo de bienes en la Gaceta de la Habana, lo que significa que previamente habían sido declarados infidentes. A partir de las fuentes primarias hemos intentado construir un análisis histórico explorando la prosopografía como método de estudio de las trayectorias vitales de los protagonistas. En la reconstrucción secuencial de los hechos de nuestra investigación nos interesa el análisis causal, hemos tenido en cuenta la dimensión sociológica y discursiva y la significación histórica de relaciones de dominio coloniametrópoli.

La estructura de la investigación se ha dividido en tres partes: la primera parte es una aproximación a la educación en Cuba como reflejo de la política colonial en el siglo XIX; la segunda parte analiza la evolución de la política educativa en la isla; y la tercera parte se centra en el protagonismo de los catedráticos en el proceso independentista y la supresión de los institutos. Al final, se aportan las conclusiones de la investigación, sugerencias de futuras investigaciones, las fuentes documentales y bibliográficas utilizadas.

\section{| La educación en Cuba como reflejo de la política colonial y como factor de nacionalización en el siglo XIX|}

Para un conocimiento general de la etapa objeto de estudio (1863-1898) hay que considerar los antecedentes, ya que a partir de la Constitución de 1837 se establecen leyes especiales en Cuba que suponen el aislamiento de la isla del proceso liberal peninsular y ese proceso marcó el origen de la ruptura cubana (Lario, 2017, pp. 243276); Alonso Romero, 2002). En la segunda mitad del siglo XIX los gobiernos liberales

\footnotetext{
${ }^{2}$ La colección de la Gaceta de la Habana no está completa. En la Biblioteca Nacional de España (BNE), faltan varios números de diversos años y no están los siguientes años: 1871, 1872, 1877, 1878, 1879 y 1882. En la Biblioteca Nacional "José Marti”" de La Habana (BNJM) si está disponible la colección completa, no obstante, están ilocalizables algunos números sobre todo de la etapa de 1868 a 1878.

${ }^{3}$ La sociología histórica de tradición weberiana pretende interpretar y/o explicar causalmente determinados procesos históricos. Como opinaba Michael Mann (1986, vol. 1, pág.7), para muchos politólogos y sociólogos, "la teoría sociológica no se puede desarrollar sin conocimiento de la historia". Hubo una sociología que abandonó la historia y sucumbió ante la "gran teoría". Así, para Santos Juliá (1989, p. 58), "redescubrir es retornar a las fuentes", pues la teoría social ha sido desde sus primeros esbozos una reflexión sobre sociedades cambiantes en el tiempo y, por tanto, cargada de un fuerte contenido histórico. Economía y Sociedad de Max Weber (1921/1993) fue la última de las grandes construcciones sociohistóricas producidas antes de que sociólogos y antropólogos comenzaran en los años posteriores a la primera guerra mundial lo que Peter Burke (1980, p. 21) define como un "diálogo de sordos" con los historiadores.
} 
de la metrópoli tuvieron que plantearse qué política educativa establecían en la isla de Cuba para satisfacer las necesidades de las élites antillanas. Para ello se diseñó un plan de estudios con el objetivo de dar respuestas a esas demandas. El plan de instrucción pública para la isla de Cuba de 1863 se basa en la ley de 1857 de la península, sin embargo, no se aplica de forma similar a como se hace en esta. El plan desgajaba de la Universidad de La Habana los estudios de segunda enseñanza y disponía la creación de los institutos de La Habana, Santiago de Cuba, Matanzas y Puerto Príncipe.

El inicio de la insurrección en 1868 deterioró la enseñanza en la isla, muchos catedráticos de segunda enseñanza ejercieron un papel destacado alineándose con las tendencias independentistas y colaborando en la insurrección, sobre todo en la zona oriental de la isla (Cañizares Márquez, 2018).

Consideramos la educación impartida en Cuba en el siglo XIX como un factor de nacionalización de las élites criollas. Desde la metrópoli existía una obsesión con la idea de la patria en peligro, una reiterada llamada a sentir la grandeza de la madre patria, por lo que se intentaba españolizar a los jóvenes cubanos a través de una instrumentalización nacionalista del sistema educativo. En el devenir de la identidad nacional como proceso histórico-cultural, los catedráticos de institutos públicos tuvieron un relevante protagonismo. Como queda reflejado en la investigación, muchos catedráticos fueron cesados en la etapa de la Guerra Grande por motivos políticos. A partir de entonces se hizo patente la existencia de la nación cubana (Opatrný, 2005), y de su identidad como pueblo, aunque la conciencia nacional había comenzado a configurarse desde 1837 con las leyes especiales que la Constitución establecía para los territorios de ultramar.

Si el colonialismo y el imperialismo constituían la causa fundamental de la negación de la nación cubana, la lucha contra ellos era la reafirmación primaria de la nación y la expresión más fuerte de identidad, las autoridades de la metrópoli eran conscientes de la importancia del sistema educativo como elemento de integración social y de vertebración política, por ello se centraron en la vigilancia de los catedráticos. Las políticas coloniales aplicadas en Cuba en el siglo XIX fueron el resultado de unos procesos históricos imperialistas que impusieron las condiciones de dependencia que tuvieron su reflejo en la educación (Carnoy, 1995). La segunda enseñanza que transmitían la mayoría de los catedráticos en Cuba en las etapas iniciales de la Guerra de los Diez Años estaba marcada por la idea de la conversión de la nacionalidad en nación a partir del proceso de colaboración de los profesores con las élites burguesas y las demás capas sociales que se van sumando al ideal independentista, y en ese contexto ni el anexionismo ni el reformismo podían ser las soluciones para la cuestión cubana, sí lo podría haber sido una autonomía plena (único medio de salvar la unidad amenazada) como la que dieron los ingleses a Canadá, y que en 1869 defendía la élite burguesa habanera ${ }^{4}$.

Las principales corrientes políticas en Cuba fueron el anexionismo, el reformismo, la asimilación (es decir, dar a la isla el mismo trato legislativo que las demás provincias

${ }^{4}$ Documento manuscrito e informe de Antonio Bachiller y Morales según acuerdo de la reunión secreta celebrada el día 13 de enero de 1869 en casa del Marqués de Campo Florido en La Habana. BNJM.

SHJ, 2022, 2(I), pp. 46-68. ISSN: 2792-3967

49 
españolas), el autonomismo (que suponía conceder a Cuba un régimen de gobierno propio dentro de la soberanía española) y el independentismo. Los nacidos en Cuba estaban en gran modo a favor de la independencia y rechazaban por igual al colonialismo español y al anexionismo norteamericano. ${ }^{5}$ La nacionalidad cubana comenzaba a surgir en forma de oposición de intereses económicos entre los grandes terratenientes cubanos y las clases dominantes en España.

En la Guerra de los Diez Años, la etapa de 1868 a 1871 es una fase decisiva en la política educativa colonial en la Gran Antilla y en la rebelión de los catedráticos que llevaron a las autoridades de la isla a suprimir los institutos en 1871. En el período de entreguerras (1878-1895) se consolida un pensamiento liberal partidario de luchar contra la oligarquía, el colonialismo, el imperialismo y la burguesía que tiene a José Martí como líder indiscutible, quien pudo aprovechar las experiencias de esta etapa para llevar a cabo su proyecto independentista, que fue posible porque antes se habían creado las condiciones necesarias para la formación de la conciencia nacional de la élite criolla. Martí realizó parte de su formación en el Instituto de La Habana ${ }^{6}$, publicó un artículo en El Avisador Hispano-Americano de Nueva York el 24 de enero de 1889 con motivo de la muerte de Antonio Bachiller y Morales, uno de sus profesores y director del instituto hasta 1869 , en que fue cesado por infidente, elogiando su trayectoria y su cariño a la patria (Vázquez Pérez, 2021). Martí intercambió escritos y cartas con algunos de sus profesores del Instituto de La Habana, sus escritos son el reflejo de sus concepciones en torno a los movimientos políticos contra España y la independencia de Cuba hasta 1889.

En la guerra de 1895 muchos políticos españoles pensaban que se trataba de una guerra civil, pero en realidad era una guerra de liberación nacional (Stucki, 2017). La guerra de Cuba tenía una dimensión internacional muy relevante por el deseo norteamericano de adquirir la isla, por ello el factor geopolítico es el auténticamente dominante y determinante en la cuestión de $\mathrm{Cuba}^{7}$ y hay que destacar que La Habana ejerció un fuerte centralismo en todos los aspectos, fue la metrópoli del Caribe en la geopolítica del siglo XIX y la ciudad más cosmopolita de España, fue la primera ciudad en instalar avances tecnológicos, por delante de Madrid y Barcelona (Leal Spengler, 1988).

\section{Evolución de la política educativa en Cuba en el siglo XIX |}

La instrucción pública en Cuba hasta 1879 está marcada por los planes de estudios de 1842 y 1863 . Aunque similares a los de la península su aplicación en la isla va a ser muy diferente $y$ en Cuba van a perdurar prácticas del pasado como la limpieza de sangre ${ }^{8}$ que

\footnotetext{
Entre los que estaban a favor del anexionismo de la isla de Cuba a Estados Unidos destacó el catedrático del instituto y de la Universidad de La Habana José Ignacio Rodríguez, que estuvo presente en la firma de la Paz de París de 1898 (Rodríguez, 1900). Para el diputado a Cortes Carlos Sedano y Cruzat la cesión de la isla no hubiese sido deshonroso para España (Sedano y Cruzat, 1912, pp.156-157 y 432).

${ }^{6}$ ANC, Fondo Instrucción Pública, legajo número 218, número de orden 13670, año 1869. Expediente de José Martí y Pérez en el Instituto de Segunda Enseñanza de La Habana.

7 La cuestión de la anexión a Estados Unidos es magistralmente analizada por Javier Rubio (1995 y 2004).

${ }^{8}$ En la península era requerida en la Universidad Central de Madrid, en el Colegio Naval, el Colegio de Artillería y en el Colegio de Infantería, así como en el acceso a diferentes carreras administrativas y burocráticas; en Cuba se requería en la Universidad de La Habana y también en los Institutos de Segunda Enseñanza. El 18 de mayo de 1865 fue publicada en la Gaceta de Madrid una ley, por SHJ, 2022, 2(I), pp. 46-68. ISSN: 2792-3967
} 
consistía en probar la legitimidad con las partidas de bautismo y con testigos que tenían que acreditar unas cualidades sociales de la familia. En 1842 entró en vigor la primera Ley General de Instrucción Pública para las islas de Cuba y Puerto Rico. Con esta ley España se propuso controlar y centralizar la educación en ambas colonias: se desplazó a la Sección de Educación de la Sociedad Económica de La Habana del control de la enseñanza, estando las enseñanzas técnicas a cargo de la Sociedad Económica de Amigos del País y de la Junta de Fomento. A partir de entonces, la Inspección General de Estudios de Cuba, presidida por el Gobernador, obtuvo la categoría de instancia superior para las dos colonias en las cuestiones relacionadas con la enseñanza. Hasta 1842 no se contemplaba enseñanza de niños "de color" en la política colonial, tan solo interesó su evangelización, su adoctrinamiento y su conversión al catolicismo.

El plan de estudios de 1842 supuso la primera y mayor reforma de la Universidad. Hasta ese año no había desaparecido la confusión existente entre los niveles de la primera enseñanza y la segunda enseñanza; se crearon los institutos en 1863, aunque desde 1728 existía universidad en La Habana, donde se impartía la segunda enseñanza en colegios mayores. Se elevaba al profesorado al rango de carrera civil del Estado y se establecía la Inspección, se daba una nueva forma a los poderes administrativo y directivo, también se creaba una Junta Superior consultiva que, junto con el Gobernador Superior Civil, constituía el centro de la administración y dirección de la instrucción pública. En 1855, con el segundo gobierno del general José Gutiérrez de la Concha, se crearon las Escuelas Generales Preparatorias de La Habana y Santiago de Cuba, y en 1857 se estableció en Guanabacoa la Escuela Normal de Maestros de Enseñanza Primaria (Bachiller y Morales, 1859).

En cuanto a la organización de la instrucción pública el territorio de la isla de Cuba en 1863 estaba dividido en dos departamentos y subdividido en cuatro círculos de instituto y cuarenta y dos distritos municipales, con la administración central en La Habana, donde se hallaba la Universidad, la Junta Superior de instrucción pública y el Gobernador Superior Civil, que era el jefe superior del ramo. El plan de 1863 reafirmaba la centralización, era adaptación de lo dispuesto en la Península por el duque de Rivas en 1836, cuyas principales aportaciones pasaron después al Plan Pidal de 1845 y a la ley Moyano de 1857. Por resolución de 28 de septiembre de 1863 del gobernador Domingo Dulce se creaban los institutos de La Habana, Santiago de Cuba, Matanzas y Puerto Príncipe y como se había suprimido la facultad de filosofía, los catedráticos pasaban al recién creado Instituto de la Habana. Los institutos de La Habana y Santiago de Cuba eran completos, en ellos se impartían la segunda enseñanza y los estudios de aplicación.

La segunda enseñanza continuó impartiéndose en los colegios privados que se incorporaron a los institutos de segunda enseñanza a partir de 1863, también pasaron a los institutos las asignaturas de las anteriores Escuelas Generales Preparatorias y se establecieron dos Escuelas Profesionales en La Habana y Santiago de Cuba. Poco se implicaron los gobernadores en la educación secundaria pública, los municipios tampoco 
cumplieron con sus obligaciones, no pagaban a los maestros con regularidad ni atendían el sostenimiento de las escuelas. Se fortaleció la enseñanza privada con nuevos colegios privados donde existía una buena calidad en la enseñanza, pero solo podían acceder los alumnos de la élite colonial, los directores de estos centros podían modificar los planes de estudio, añadiendo asignaturas, en muchos de estos centros contaban con la enseñanza de la música, el deporte, las artes plásticas, la gimnasia y la esgrima, que trascendieron el ámbito escolar para estar presentes en sociedades filarmónicas, conservatorios, gimnasios y escuelas de equitación.

En Santiago de Cuba, Matanzas y Puerto Príncipe los institutos comenzaron a funcionar en 1864 y en La Habana en 1863. En carta de 12 de julio de 1864 se dio cuenta a la reina de la necesidad de crear estudios generales de la segunda enseñanza en los Institutos de Matanzas y Puerto Príncipe, autorizados solo para los de aplicación a las profesiones industriales. Por Real Orden de 19 de enero de 1865 se ampliaban los Institutos de aplicación de Matanzas y Puerto Príncipe a los estudios generales de segunda enseñanza desde el año académico de 1865 a 1866. Desde 1866 a 1871 hubo proyectos de creación de institutos de segunda enseñanza en Cienfuegos, Santa Clara y Pinar del Río que no llegaron a materializarse por la guerra.

Según el Plan de Estudios de 1863, todas las asignaturas de todos los niveles de enseñanza se estudiaban por los libros señalados en listas que el Gobierno Supremo publicaba cada tres años. La selección de las obras la hacía el Gobierno Supremo mediante concurso, que se publicaba en la Gaceta de La Habana, oyendo al Real Consejo de Instrucción Pública. Las propuestas de libros de textos que se hacían desde Cuba debían ir informadas por la Junta Superior de Instrucción Pública. La legislación posterior no introdujo modificaciones. A partir del plan de 1880 el ministro de Ultramar comunicaba al Gobernador General de Cuba la relación de obras de texto y los Catedráticos de Institutos de Segunda Enseñanza elegían los textos de esa relación previa.

El 26 de enero de 1867 la reina Isabel II aprobó el Reglamento de la Junta Superior de Instrucción pública de la isla de Cuba. La Junta superior de Instrucción pública de la isla de Cuba se componía del Gobernador Superior civil que era su presidente nato, de un vicepresidente, cuatro vocales natos, doce vocales ordinarios y un secretario. Las atribuciones de la Junta eran, entre otras, emitir su dictamen en: la creación o supresión de cualquier establecimiento público de enseñanza, la creación o supresión de cátedras, expedientes de separación de maestros de instrucción primaria, en los que tenía por objeto establecer institutos públicos para la segunda enseñanza, en los que se formaban a consecuencia de las quejas de los prelados Diocesanos sobre libros de texto y explicaciones en que se emitían doctrinas perjudiciales para la buena educación religiosa de la juventud. El 13 de junio de 1867 se aprobó el Reglamento para la inspección de la Instrucción Pública en la isla de Cuba. La inspección la ejercía el Gobierno por medio de los vocales de la Junta Superior de instrucción pública. En los expedientes de visitas los inspectores debían hacer constar de forma prioritaria el grado de instrucción, aptitud y moralidad de los profesores, su celo por la enseñanza, los métodos que seguían en la 
enseñanza, lo libros de textos utilizados y las doctrinas que se vertían en las explicaciones.

En 1867 se aprobaba definitivamente el Reglamento de los establecimientos de segunda enseñanza que regía con carácter de interino desde el 29 de septiembre de 1863, con las modificaciones introducidas por el Consejo de Instrucción Pública. Ese año también se publicaba el Reglamento para la provisión de las cátedras de la Universidad, Escuelas Superiores y Profesionales e Institutos de segunda enseñanza y para las traslaciones, ascensos y jubilaciones de los Catedráticos de la isla de Cuba. Ya en 1867 la enseñanza pública y privada se daba en Cuba en todos los grados, desde la escuela de párvulos hasta la Universidad. De acuerdo con Agüero y Sánchez (1867, pp. 13-15), el 1 de enero de 1867 había en Cuba 712 escuelas de primeras letras, con 27.780 alumnos y 1.284 maestros; 24 establecimientos de segunda enseñanza, incluidos dos seminarios conciliares, con 215 profesores y 1.818 alumnos; 12 escuelas profesionales con 34 profesores y 188 alumnos; una Universidad con 37 profesores y 536 alumnos. Por lo tanto, un total de 749 establecimientos, 1.570 profesores y 30.322 alumnos de todas clases y grados, que en ese año escolar costaron al Estado, a los ayuntamientos y a las familias un total de 3.358 .328 escudos.

Hay que destacar una consulta que el Gobernador Superior civil elevó el día 19 de julio de 1867 a la Junta Superior de Instrucción pública con motivo de haberse publicado, sin previa censura, el periódico titulado La Crónica en el colegio de San Francisco de la Habana. Quería saber si reportaba alguna ventaja la publicación de periódicos en los institutos de enseñanza. La Junta en sesión de 16 de septiembre de 1867 acordó por unanimidad aprobar el informe donde aconsejaba no autorizar la publicación de perniciosos folletines ni periódicos en los institutos de segunda enseñanza. Consideraban que el periódico "es peligroso y que sus consecuencias no pueden menos de ser fatales a la instrucción y carácter de los que inconsideradamente se entreguen a él"'. El Gobernador Superior civil con fecha de 8 de enero de 1868 dispuso que desde ese día quedaban prohibidas todas las publicaciones de periódicos en los colegios de la isla. Es una de las pruebas que demuestran que en los colegios e institutos de segunda enseñanza ya se estaban fraguando la insurrección.

Con el inicio de la guerra el 10 de octubre de 1868 empeoró el estado de la enseñanza y muchos proyectos se paralizaron como el proyecto para la educación de pobres, negros y chinos y en 1871 se suprimieron los institutos por ser fueros de insurrección. Terminada la Guerra Grande especial atención merece el Plan de Estudios para la isla de Cuba de 7 de diciembre de 1880 que establecía la necesidad de crear un instituto en cada capital de provincia. Desde la reforma de 1871, que suprimía los institutos, solo existía en la isla de Cuba el instituto provincial de segunda enseñanza de La Habana. A partir del plan de 1880 se vuelven abrir los institutos que habían sido suprimidos en Santiago de Cuba, Matanzas y Puerto Príncipe y se inauguran dos nuevos institutos en Santa Clara y Pinar del Río. El Plan de Instrucción Pública de 1880 disponía que se

${ }^{9}$ Gaceta de la Habana de 10 de enero de 1868.

SHJ, 2022, 2(I), pp. 46-68. ISSN: 2792-3967

53 
establecieran una o más escuelas públicas para niños de color, con el objeto de que recibieran la primera enseñanza elemental dirigida esencialmente a la parte moral y religiosa, en octubre de 1882 había ochenta escuelas elementales para niños "de color" en la isla de Cuba.

El Plan de Instrucción Pública de 1880 restableció las enseñanzas profesionales que habían sido suprimidas en 1871, se restablecían las enseñanzas de Veterinaria, Profesor Mercantil, Náutica, Maestro de Obras, Aparejadores, Agrimensores y Maestros de Primera Enseñanza. Las enseñanzas de artes y oficios habían sido promovidas y controladas por la Sociedad Económica de Amigos del País de La Habana y la Junta de Fomento. El 29 de julio de 1886 fue aprobado el Reglamento de la Escuela y en 1887 un Real Decreto incorporó la Escuela al régimen general de Instrucción Pública. Se impartían enseñanzas para operarios, constructores civiles, mecánicos, y químicos industriales. El Plan de 1880 establecía la necesidad de crear una escuela de maestros primarios en cada capital de provincia, con una escuela práctica anexa para que los aspirantes a maestros pudieran ejercitarse en ella. En octubre de 1881 el número de escuelas de instrucción primaria en las provincias de la isla ascendía a un total de 912, y asistían 34.895 niños de ambos sexos (Liras, 1894). Se habían creado más de 200 escuelas, muchas de ellas rurales, desde que se hizo cargo del Gobierno el General Ramón Blanco.

El 20 de julio de 1882 se aprobó un Reglamento para las escuelas Normales de Maestros de la provincia de La Habana que debían ser las encargadas de formar los maestros/as para las escuelas primarias de niños y de niñas. No obstante, hasta 1890 no se establecieron escuelas normales para la formación de maestros en La Habana. Por Real Decreto se creaban dos Escuelas Normales Superiores de Maestros y otras dos de Maestras que se establecieron una de cada sexo en las respectivas capitales de Cuba y Puerto Rico. Después de haber transcurrido veintidós años desde el cierre de la escuela de Guanabacoa en 1868, se restablecieron las Escuelas Profesionales y se indicaba la necesidad de crear escuelas normales, que no llegaron a establecerse hasta 1890 (Cabrera e Ibarra, 2010).

En 1882 se vuelven abrir los tres institutos suprimidos -Matanzas, Puerto Príncipe y Santiago de Cuba- y se crean los Institutos de Pinar del Río y Santa Clara. Los educadores del momento especificaron las deficiencias del plan y a través de las revistas pedagógicas señalaron posibles soluciones a los males de la enseñanza. En La Habana se fundó en 1882 la Escuela Preparatoria de Artes y Oficios que vino a atender la necesidad que tenía la Isla de Cuba de trabajadores cualificados. En 1884 se organizó el primer Congreso Pedagógico en Matanzas para conseguir mejoras en la educación y el cumplimiento de lo dispuesto en el plan de 1880, impulsó iniciativas como la Institución Libre de Enseñanza creada en Matanzas a imagen de la creada en España en 1876 por Francisco Giner de los Ríos, y la Liga contra la Ignorancia, iniciativa de Enrique José Varona, Antonio Bachiller y Morales y Manuel Valdés Rodríguez (Varona, 1901). Hay que destacar también el importante papel que ejercieron en la educación de adultos los Liceos Artísticos y Literarios y las sociedades regionales españolas. 
En 1882 se creó la Asociación de Profesores de la Isla de Cuba ${ }^{10}$, que contó con un periódico, El Profesorado de Cuba, fundado en agosto de 1882. Un grupo de profesores e intelectuales crearon en 1882 la Asociación Liga contra la ignorancia, encaminada a fomentar, por el esfuerzo individual y colectivo, la difusión de la educación popular. El 15 de noviembre de 1885 los Catedráticos de la Universidad, de la Escuela Profesional y del Instituto de segunda enseñanza de La Habana dirigieron un escrito a los diputados y senadores cubanos del partido Unión Constitucional con el fin de que gestionaran en la Corte la total unificación de la carrera del profesorado español. El profesorado de la isla de Cuba permanecía todavía como ramo aparte del profesorado peninsular. A pesar de todos los decretos, las promesas formales de asimilación en la enseñanza jamás se llevaron a la práctica, aunque sí se aplicaron en todos los ramos de la administración.

El 14 de octubre de 1883 se fundó en Matanzas una Institución Libre de Enseñanza. La Junta Provincial de Matanzas estaba al frente del movimiento progresista en la instrucción pública, y la Asociación de Profesores de la Isla de Cuba decidió celebrar allí el primer Congreso Pedagógico de la isla de Cuba en 1884. Una de las reivindicaciones fue desarrollar la enseñanza esencialmente práctica y racional "que tienda a desarrollar los sentimientos patrióticos"11.

En los Liceos artísticos y literarios, entre sus objetivos estaban fomentar las letras, las ciencias y las bellas artes, dar clases gratuitas, ofrecer cursos de idiomas, celebrar concursos literarios, realizar representaciones teatrales, ofrecer conciertos y bailes y promover actividades culturales, pero en algunos de ellos (Regla, Matanzas) los fines políticos eran más relevantes que los artísticos y se convirtieron en centros revolucionarios. En 1870 apareció un anuncio en el Diario de la Marina referente a la necesidad de "españolizar deliberadamente los espectáculos que allí se efectuaran"12. La creación de los liceos se aceleró con el fin de la Guerra de los Diez Años, para contrarrestar la acción de los elementos españoles integristas a ultranza, que se agrupaban en los casinos españoles, el de La Habana se inauguró el 15 de agosto de 1869; también existía una oferta educativa en las sociedades regionales españolas, las más importantes fueron el Centro Gallego y el Centro Asturiano. En 1878 se abrió un colegio para la enseñanza de sordomudos (Cabrera Rodríguez, 1890) y ciegos, en 1882 el colegio fue clausurado por el gobierno, a pesar de que el Plan de Instrucción Pública de 1880 disponía en el artículo 128, que el gobierno debía promover la creación de estos centros. No olvidamos la relevancia que empezaba a adquirir la educación física y el deporte (Jorrín, 1886), las Asociaciones de socorros mutuos y gremiales y lecturas en las fábricas de tabaco.

Debido a la crisis económica por la que atravesaba la isla en 1885, el Ministerio de Ultramar comunicó al Gobernador General una Real Orden por la que en vista de los

\footnotetext{
${ }^{10}$ En 1845 Mariano Dumas Chancel y Juan Manuel Enríquez, director del Colegio de Humanidades de Jesús, habían proyectado la creación de una asociación del profesorado. Dumas fue nombrado director del Colegio de Colón en Cienfuegos y la idea no prosperó. En 1868, José Alonso y Delgado, director del Colegio de San Francisco de Asís en La Habana, también propuso la creación de una Asociación de Maestros de Escuela, pero la insurrección de 1868 tampoco permitió la viabilidad del proyecto.

${ }^{11}$ Revista de Enseñanza, 1 de noviembre de 1885.

12 Diario de la Marina de 1 de febrero de 1870.

SHJ, 2022, 2(I), pp. 46-68. ISSN: 2792-3967
}

55 
proyectos de economías referentes a los Institutos de Segunda Enseñanza se consideraba que las Diputaciones Provinciales, aunque tenían el deber de costear a estas escuelas difícilmente podían hacerlo por la falta de recursos por los que atravesaba la isla. El Rey Alfonso XII con el propósito de que ninguna provincia quedara privada de los beneficios de dichos institutos y de hacer menos costoso para el Estado el sostenimiento de los mismos resolvió, entre otras cosas, que desde ese momento serían desempeñadas por un solo profesor en los Institutos de Pinar del Río, Santiago de Cuba, Santa Clara, Puerto Príncipe y Matanzas, las dos cátedras de Latín y Castellano, por otro las dos de Matemáticas, por otro la de Retórica y Poética y la de Lógica y Filosofía Moral, por otro la de Historia Natural con principios de Fisiología e Higiene y la de Agricultura. El Instituto de la Habana continuaba organizado en la misma forma que tenía hasta la fecha. Con estas medidas se reducían veinte catedráticos en los institutos públicos de Cuba; a excepción del instituto de La Habana, en los otros cinco institutos se reducían cuatro catedráticos por instituto. Por Real Decreto de María Cristina dado en San Sebastián el 3 de septiembre de 1892 se establecía que las Diputaciones provinciales quedaban encargadas, desde el 1 de julio de 1892, del sostenimiento y pago de los Institutos de segunda enseñanza de sus respectivas provincias, tanto en personal como en material.

En 1896, por la política represiva de Valeriano Weyler, fueron suspendidas las clases en los institutos de Pinar del Río, Santa Clara, Matanzas, Puerto Príncipe y se clausura el instituto de Santiago de Cuba $^{13}$ y el de La Habana perdió gran cantidad de alumnos y profesores. También sufrieron las consecuencias de la guerra las escuelas preparatorias, las escuelas normales y las de artes y oficios. Una vez finalizada la guerra en 1898 vuelven a abrirse los institutos anteriormente suprimidos.

\section{| El protagonismo de los catedráticos en el proceso independentista y la supresión de los centros de enseñanza |}

La insurrección del 10 de octubre de 1868 puso de manifiesto el conflicto existente entre las tendencias liberales centralistas y las autonomistas e independentistas. Muchos catedráticos de segunda enseñanza ejercieron un papel destacado en este enfrentamiento alineándose con las tendencias independentistas y colaborando en la insurrección, sobre todo en la zona oriental de la isla. Con el decreto de Caballero de Rodas de 30 de noviembre de 1869 se cesa a varios catedráticos. En ese contexto, el gobernador Blas Villate y de la Hera, Conde de Valmaseda, adoptó una política fuertemente represiva, aceptó las consideraciones de Araíztegui y autorizó la reforma de la segunda enseñanza. El decreto de 10 de octubre de 1871 (la fecha coincidía con el tercer aniversario de la insurrección) suponía una serie de reformas que afectaban a los estudios y a los profesores y suprimía por cuestiones políticas, los institutos de Segunda

\footnotetext{
${ }^{13}$ Archivo Nacional de Cuba (ANC), Fondo de Instrucción Pública, Legajo número 677, número de orden 41.083, año 1896. Documentos que tratan de la clausura del Instituto de Segunda Enseñanza de Santiago de Cuba. 
Enseñanza y de Aplicación establecidos en Matanzas y Puerto Príncipe, reorganizaba el Instituto de La Habana y depuraba al profesorado:

[...] son razones de política la que piden esa supresión de los Institutos de Cuba y Matanzas: porque en esos dos establecimientos como se ha dicho se han vertido doctrinas perniciosas contrarias a la integridad de la nación y a los buenos principios religiosos: porque en ellos se ha encaminado el corazón de los jóvenes contra sus mismos padres, haciéndoles odiar a la madre patria; porque en ellos conspiraban sus profesores contra el Gobierno que les distinguió y les dio su confianza, y porque de ellos han salido muchos de los mismos con la quijotesca pretensión de hacer girones el glorioso pabellón de Castilla, bajo el cual nacieron y se criaron: rompiendo con su nacionalidad y dejando en las Cátedras sembrada la mala semilla que es necesario extirpar destruyendo esos fueros de insurrección en que con simulado intento se han pintado a los ojos de la juventud, la tiranía de los gobiernos, y la libertad de los pueblos y donde se han discutido hechos de la actual lucha mostrando sus simpatías por todo aquello que el laborantismo fragua e inventa en favor de los que ayer fueron sus maestros y hoy practican la destrucción y la ruina con la enseñada rebelión contra sus padres y la patria $[\ldots]^{14}$.

El instituto de Puerto Príncipe ya estaba clausurado desde fines de 1868, pues todos los catedráticos, a excepción de dos, abandonaron sus puestos. Se suprimía igualmente el Instituto de Segunda Enseñanza de Santiago de Cuba, quedaba habilitado el Colegio Seminario de San Basilio en Santiago de Cuba para los estudios generales de Segunda Enseñanza, y para conferir el grado de Bachiller en Artes. Para la supresión de los institutos fueron trascendentales las cuestiones políticas, como lo atestiguan los expedientes, aunque las autoridades metropolitanas también justificaban la medida con una gran cantidad de datos económicos. El jefe del negociado de instrucción pública Pelayo González el 13 de junio de 1871 estimaba por lo tanto que solo debía quedar el Instituto de la Habana. También se dio el caso de colegios privados que fueron clausurados como el colegio de El Salvador, fue cerrado el 31 de enero de 1870 conforme al artículo 225 del Reglamento, porque su director José María Zayas había desobedecido las órdenes del Gobierno.

Se declaraba Central y Provincial el Instituto de Segunda Enseñanza de La Habana y a él quedaban incorporados todos los colegios privados de Segunda Enseñanza de Cuba, dirigidos por particulares o corporaciones que no fuesen religiosas, así como los Seminarios que continuaban bajo la dependencia del Gobierno Superior Político. Quedaban relevados los ayuntamientos de la isla de la obligación que habían tenido de contribuir al sostenimiento de los Institutos.

El Instituto de la Habana como establecimiento provincial, pasaba a ser una dependencia del Gobierno Superior Político, y sostenido por el Estado que recaudaba los productos de matrículas, grados y títulos. Por lo tanto, a partir de ahora los gastos de personal y

14 Archivo Nacional de Cuba (ANC), Fondo de Instrucción Pública, Legajo 232, número 14668. Expediente de supresión de los Institutos de Matanzas, Puerto Príncipe y Santiago de Cuba, 13 de junio de 1871.

SHJ, 2022, 2(I), pp. 46-68. ISSN: 2792-3967

57 
material del instituto figuraban en los presupuestos de la isla, como las demás dependencias del Estado. El Instituto de la Habana quedaba solo reducido a los estudios generales de segunda enseñanza. Quedaban suprimidos en el Instituto de la Habana los estudios elementales de aplicación, como eran las asignaturas de Derecho Mercantil y Economía política, ya que se explicaban en la Facultad de Derecho de la Universidad. También quedaban suprimidas las asignaturas de Dibujo lineal, Aritmética mercantil y Teneduría de libros que se daban en los colegios de instrucción primaria superior que existían en la isla, en el Casino español y en colegios y academias privadas. Segregaban del Instituto de la Habana las Escuelas Profesionales que se incorporaron a éste el 31 de agosto de 1869.

A partir de ahora, con la reforma de Araíztegui, quedaba prohibido hacer los estudios de segunda enseñanza, tanto del primero como del segundo período en educación doméstica, con validez académica según permitían los artículos 19 y 222 del Plan general de Estudios. A partir del decreto de Araíztegui, los títulos de Bachiller en Artes se expedían por el Gobierno Supremo Político. También había que suprimir las cátedras de los estudios de aplicación y profesionales que se consignaron en agosto de 1869. Se declaraban cesantes a todos los que estaban en los Institutos después del 28 de septiembre de 1863 con el carácter de Catedráticos interinos. La Escuela Profesional de Agrimensores, Aparejadores y Maestros de Obras debía establecerse separadamente del Instituto de la Habana, comprendía no solo los estudios peculiares de esas profesiones sino los elementales y preparatorios para ellas.

El Gobernador Superior Político Caballero de Rodas consideraba poco satisfactorio los resultados de las Escuelas Profesionales de La Habana y de Santiago de Cuba, el 31 de agosto de 1869 quedaban suprimidas y se incorporaban al Instituto de Segunda Enseñanza de La Habana todas las asignaturas que las constituían. En 1871 con el decreto de Araíztegui, el Gobernador Superior Político declaraba suprimidas las Escuelas profesionales de Comercio y Náutica, que estaban agregadas al Instituto de La Habana. Se creaba una Escuela profesional de Agrimensores, Aparejadores y Maestros de Obras en La Habana.

El decreto de 1871 también reforma la Universidad. Como recoge la Gaceta de la Habana, muchos de los Catedráticos de la Universidad de La Habana huyeron al extranjero al estallar la insurrección en Yara "para continuar allí su obra de conspiración, cuyos nombres son harto conocidos como enemigos de la patria, que arrastraron tras sí a los jóvenes a la rebelión" y se tuvieron que hacer cargo de las enseñanzas profesores auxiliares. La Universidad tenía que corresponder a los intereses del Gobierno y de la enseñanza "encargándola a un profesorado digno e ilustrado, que no inculque en la juventud perniciosas doctrinas, ni convierta la Cátedra de la Ciencia en tribuna revolucionaria". ${ }^{15}$

En 1871 se llevó a cabo la reorganización de las escuelas públicas de primera enseñanza elemental que fueron clausuradas a consecuencia de las circunstancias por las que había

15 Gaceta de la Habana 11 de octubre de 1871 
atravesado el país y por el estado de atraso en que se encontraban los fondos municipales. Se costeaban con fondos públicos y necesitaban "maestros idóneos que sean dignos de merecer la confianza de este Gobierno por sus ideas y doctrinas que correspondan a los verdaderos fines e intereses de la Religión, de la familia y del Estado".

También se procedió a la depuración de los libros de texto. Los Catedráticos de los Institutos, Escuelas Profesionales y Universidad no podían designar para la asignatura de su cargo ninguna obra que no se incluyera en las que se relacionaban para cada materia. Los directores de los colegios privados de segunda enseñanza de cualquier clase tenían que escoger para cada asignatura la obra que designaban los respectivos Catedráticos del Instituto de La Habana. A los profesores que enseñaran por otros textos se les suspendería de sus respectivos cargos.

A partir de 1868 muchos catedráticos evolucionaron de posiciones autonomistas 0 asimilistas a posiciones claramente independentistas. Los expedientes gubernativos ${ }^{16}$ aportan una radiografía muy aproximada sobre los catedráticos que iniciaron el camino de la insurrección. El independentismo de los catedráticos está directamente relacionado con la evolución de la política educativa en la colonia. Aunque la legislación educativa era muy similar a la de la metrópoli, su aplicación en la isla de Cuba era muy diferente. Esto explica que los catedráticos antillanos se sintieran discriminados respecto a los peninsulares y su percepción de desigualdad fue en aumento con acontecimientos que influyeron en la construcción y deconstrucción de sus propias narrativas identitarias. La evolución de su pensamiento hacia posiciones independentistas forjó su particular historia y fue un factor que condicionó la evolución de la estructura política, social y cultural de la sociedad colonial cubana ${ }^{17}$.

La defensa de una política educativa similar a la de la península y de los propios intereses favoreció la cohesión social del grupo, el consenso político y los proyectos asociativos que más adelante se materializaron en las asociaciones de profesores. La supresión de los institutos en 1871 por parte de la metrópoli consiguió crear una opinión pública muy contraria a las autoridades de la isla, frente al discurso institucional.

La validez de los resultados depende de la amplitud de la muestra y, en nuestro caso, para la etapa de 1868 a 1878, y con el objetivo de ser exhaustivo, la muestra ha sido la totalidad del colectivo. Es decir, hemos documentado todos los catedráticos que impartieron docencia en ese período, y hemos constatado que en la Guerra de los Diez Años el sesenta y cinco por ciento de los catedráticos de instituto fueron acusados de delitos de infidencia (principalmente de rebelión), por colaborar con los independentistas, separados de sus cátedras, encarcelados y algunos ejecutados (Cañizares Márquez, 2018). Sus nombres se publicaban en la Gaceta de la Habana para general conocimiento y sus bienes eran embargados. Estos actores jugaron un papel muy relevante como agentes de transmisión de ideas y dinamización política de sus alumnos, como abiertamente lo reconocían las autoridades de la isla, y se puede comprobar en

\footnotetext{
${ }^{16}$ La mayoría de los expedientes están depositados en el Archivo Nacional de Cuba y unos pocos se encuentran en el Archivo Histórico Nacional en Madrid.

${ }^{17}$ La sociología de las relaciones coloniales ha sido magistralmente analizada por López Segrera (1982). SHJ, 2022, 2(I), pp. 46-68. ISSN: 2792-3967
}

59 
varios expedientes en esta investigación. La apelación a la defensa de la patria cubana fue una constante de este colectivo a partir de 1868. Por supuesto, el contexto de la guerra ayudaba a la difusión de las ideas de los catedráticos a sus alumnos en un conflicto que los españoles consideraban de carácter colonial pero muchos cubanos lo consideraban de liberación nacional.

El protagonismo de los catedráticos en Puerto Príncipe, Matanzas y Santiago de Cuba es indiscutible, como se puede apreciar en el expediente de supresión de los institutos de estas localidades. Por medio de esta fuente primaria se puede comprender el nivel de implicación del colectivo de catedráticos en el proceso insurreccional. Las autoridades metropolitanas ponían en cuestión la labor del profesorado en los institutos públicos y se sancionaba a los catedráticos por motivos políticos. Las cifras de catedráticos infidentes nos indican que los institutos eran espacios de sociabilidad insurreccional donde se difundieron ideas independentistas y los catedráticos conformaban verdaderas células de conspiración y oposición política como queda avalado en los diferentes expedientes gubernativos de catedráticos y en los expedientes de supresión de los institutos. Las autoridades de la isla manifestaban que en los institutos se difundían "doctrinas perniciosas contrarias a la integridad de la nación y a los buenos principios religiosos", en los institutos "conspiraban sus profesores contra el Gobierno que les distinguió y les dio su confianza" y por ello era necesario destruir “esos fueros de insurrección”. La lucha por la independencia originó un pensamiento que tuvo su reflejo en la política educativa que aplicaron desde la metrópoli, de ahí la supresión de los institutos y la depuración del profesorado. La represión de estos años se hizo sentir de forma trágica con el fusilamiento de ocho estudiantes de medicina el 27 de noviembre de 1871 (Le Roy y Gálvez, 1971; Valdés Domínguez, 1969).

El gobierno del conde de Valmaseda realizó en 1871 una profunda reforma educativa que afectaba a los estudios, depuraba a los profesores y suprimía los institutos de Matanzas, Santiago de Cuba y Puerto Príncipe. También fueron clausurados los colegios privados cuyos directores eran desafectos a España y muchos profesores fueron cesados y sustituidos por otros como lo muestra las continuas alteraciones que se producían en el cuadro de profesores. A partir de entonces solo permaneció abierto el Instituto Provincial de Segunda Enseñanza de La Habana y se procedió a una auténtica depuración del profesorado y de los libros de texto, de los cuales solo sobrevivió un reducido grupo de títulos y autores. La Escuela Normal de Maestros de Guanabacoa fue cerrada en 1868 y el 31 de agosto de 1869 por un decreto de Caballero de Rodas se suprimieron las Escuelas Profesionales en La Habana y en Santiago de Cuba y fueron cesados muchos catedráticos de Instituto. El progresista Colegio La Empresa de Matanzas fue cerrado el 9 de noviembre de 1869, después de la salida de Cuba de los hermanos Guiteras por sus ideas independentistas, del colegio se llegó a decir que "no era un centro de educación, sino un nido de víboras" (Leiva Luna, 1944). En 1869 aparecieron en la Gaceta de la Habana los numerosos cambios de profesores que tenían lugar como consecuencia de los abandonos de cargos.

El Decreto de Araíztegui de 1871 señalaba de una forma extensa los defectos de la instrucción pública e indicaba las reformas necesarias para "moralizar y españolizar" a SHJ, 2022, 2(I), pp. 46-68. ISSN: 2792-3967 
las generaciones futuras. Para asegurar la dominación de España en la isla, el gobierno debía dar más importancia a la religión. En su opinión, se había descuidado la educación moral y religiosa, había un exceso de libertad en la enseñanza que había degenerado en anarquía y la consecuencia de todo ello fue la insurrección.

Desde el inicio de la guerra del 68 había comenzado el proceso que llevó a la abolición de la esclavitud en 1886, comenzaron a organizarse agrupaciones de personas libres "de color" y muchas de ellas tenían colegios de primeras letras, evolucionaron hacia posiciones independentistas. En las zonas insurrectas se abrieron escuelas, se alfabetizó a soldados y campesinos y se preparó una Cartilla de Alfabetización. En la década de los 80 se aprobaron dos importantes medidas, la admisión de mujeres y la de gente "de color”, pero la matrícula en ambos casos fue escasa (Barcia, 1987).

Con la supresión de los institutos en 1871 se pretendía eliminar la organización formal, los espacios de sociabilidad que posibilitaban la difusión de "ideas perniciosas". Las medidas adoptadas, focalizadas en las estructuras del conflicto, ponen de relieve que los catedráticos contaban con gran capacidad de influencia en sus alumnos y empezaron a configurar una mentalidad colectiva común en torno a la adquisición del sentimiento de pertenencia a una identidad nacional propia independiente de la metrópoli. A la Universidad de La Habana, por razones de economía y política, se le privó del derecho de otorgar el doctorado en las facultades mayores (Derecho, Medicina y Farmacia), excepto en la de Teología, y se limitaron los grados en las menores (Filosofía y Ciencias Naturales y Exactas), restringidos al bachillerato. También era obligatorio utilizar textos declarados oficiales. A partir de la reforma de 1871 los estudios de doctorado se debían cursar en las Universidades de la Península, las oposiciones a Cátedras se realizarían en la Universidad Central a la que debían acudir los que aspiraran al grado de Doctor. Este grado se restableció en Cuba por Decretos del Gobierno General de 5 y 10 de septiembre de 1878, tras la paz de Zanjón.

Incluso se llegó a plantear la conveniencia de cerrar la Universidad ${ }^{18}$ y sustituirla por colegios especializados y la españolización de los claustros, medidas que no se lograron, a excepción de la centralización. Había diferencias notables entre la Universidad de La Habana y las de la Península en cuanto a las asignaturas impartidas, pero también respecto a la remuneración de los profesores, que era inferior en La Habana. Estudiar en la Universidad de La Habana era más caro que en cualquier otra universidad de la Península. La matrícula universitaria se vio muy perjudicada entre 1869 y 1872 y entre 1895 y 1898, y muchos jóvenes se marcharon de Cuba para cursar sus estudios superiores, fundamentalmente a Estados Unidos o Francia. Con la promulgación del plan de estudios de 1880 las facultades podían ofertar los grados de licenciado y doctor.

Con la supresión de los institutos las autoridades de la isla ya reconocían abiertamente que muchos catedráticos colaboraban con el independentismo desde antes incluso de la creación de los establecimientos de segunda enseñanza y asumían la imposibilidad de

\footnotetext{
${ }^{18}$ ANC, Fondo de Instrucción Pública, Legajo número 726, número de orden 45.978, documentos que se refieren a distintas comunicaciones sobre la conveniencia de cerrar facultades de la Universidad de La Habana con fines políticos y otros particulares no afectos al personal.
}

SHJ, 2022, 2(I), pp. 46-68. ISSN: 2792-3967

61 
controlar el acceso a cátedras para que éstas fuesen ocupadas por leales al gobierno. La relación de catedráticos en la etapa de 1868 a 1878 en los cuatro institutos de la isla de Cuba es la siguiente (entre paréntesis se indican los infidentes acusados de delitos de rebelión, por lo que fueron encarcelados, separados de sus cátedras y, en algunos casos, ejecutados):

En el instituto de La Habana: Antonio Bachiller y Morales (Infidente), Emilio Auber y Noya, Paulino Álvarez Aguíñiga, Fernando Páez y González, Joaquín García Lebredo y Lladó (Infidente), Antonio Ma Tagle y Granados, Manuel Fernández de Castro, José Luna y Parra (Infidente), Cristóbal Mendoza (Infidente), Ramón Querol Garríguez, Fulgencio A. Llorens (Infidente), José García Toledo (Infidente), Jesús Benigno Gálvez y Alfonso (Infidente), Francisco Morales López, Sixto Lima Macías (Infidente), Claudio André y Serpa (Infidente), Isaac Carrillo de Albornoz y O’Farrill (Infidente), Francisco Navarro, Fernando Domínguez y Domínguez (Infidente), Antonio Blanco Fernández, Torcuato Artola, Manuel J. Cañizares y Venegas, José de J.Q. García (Infidente), José Francisco Arango (Infidente), José García de Arboleya y Duval (Infidente), Manuel Álvaro y Valdés (Infidente), Andrés María Foxá y Leconda (Infidente), Baltasar Velázquez de Cuellar y Patrón, José María García de Haro, Manuel Espinosa e Inés (Infidente), Benito José Riera, Pedro Arias y Ávalos, Adolfo Gallet Duplesis, Tomás Caballero Heillinger (Infidente) y Bonifacio Ávila Hernández.

En el instituto de Santiago de Cuba: José Ramón de Villalón y Hechevarría (Infidente), Benito José Riera, Manuel Ramón Fernández Rubalcaba, Francisco Losada, Federico García y Copley (Infidente), Pedro Celestino Salcedo y Cuevas (Infidente), José Antonio Alayo y Martí, Francisco González Santos (Infidente), Pedro Valdés Tapia (Infidente), Francisco Martínez Betancourt (Infidente), Tomás Mendoza y Durán (Infidente), presbítero Francisco de Paula Barnadas, Ismael José Bestard (Infidente), Darío Crespo y Quintana (Infidente), Rodrigo Rodríguez y Rodríguez (Infidente), Vitaliano de Jesús Martínez, Ambrosio Valiente y Duany (Infidente), y Bernardo Nuñez de Villavicencio (Infidente) y Rafael Fabra.

En el instituto de Matanzas: José Quintín Suzarte Hernández Arvelo (Infidente), Francisco Valdés Rodríguez, Leonardo del Monte y Aldama (Infidente), Ramón María Estévez (Infidente), Salvador Condaminas y Casacubarta (Infidente), Sebastián Alfredo de Morales González (Infidente), Bernabé Maydagan (Infidente), Sixto Lima y Macías (Infidente), Juan Francisco Prieto y Acosta (Infidente), Emilio Blanchet Bitton (Infidente), Fernando Domínguez y Domínguez (Infidente), Juan de Melo Moreno, Pio Campuzano (Infidente), Antonio Martínez del Romero (Infidente), Domingo Cartaya (Infidente), Ildefonso de Estrada y Zenea (Infidente), presbítero Antonio Faus y Cerquera, Jorge de la Calle (Infidente), Emilio Villaverde y Fernández, presbítero Mariano Nogueras, Agapito Boises y Díaz (Infidente), Ambrosio José González (Infidente), Ramón D’Meza y del Valle (Infidente), Miguel Curchieri (Infidente), Martín Muro, Francisco María Barrena, Francisco P. Flaguer (Infidente) y Ramón Fernández Bárcenas.

En el instituto de Puerto Príncipe: José del Monte y Garay (Infidente), Fernando Betancourt Vallan (Infidente), Juan Manuel García de la Linde (Infidente), Cristóbal 
Mendoza y Durán (Infidente), Manuel de Monteverde (Infidente), Manuel Gómez y Nogueras (Infidente), José Freyre y Góngora (Infidente), Ladislao Fernández (Infidente), Federico Miranda y Agramonte (Infidente), Oliverio de Agüero (Infidente), José Antonio Pichardo, Eduardo Agramonte y Piña (Infidente), Blas López Pérez (Infidente), Francisco Benavides Márquez (Infidente), Nestor Moinelo (Infidente), presbítero Pedro Francisco Almansa (Infidente) y Joaquín Laudo y Estévez. En este instituto todos fueron separados de sus cátedras por infidentes a excepción de dos: a José Antonio Pichardo le recompensaron con el cargo de presidente de la Diputación de Puerto Príncipe y a Joaquín Laudo y Estévez se le recompensó con la cátedra de Anatomía Quirúrgica en la Facultad de Medicina de la Universidad de La Habana y llegó a ser vicerrector de dicha Universidad.

El número total de catedráticos en los cuatro institutos de la isla en la etapa de la guerra Grande (1868-1878) fue de 99, de los cuales 65 (es decir, el 65,66 por ciento) fueron separados de sus cátedras por motivos políticos (Tabla 1). En toda la etapa bélica en el Instituto de La Habana fueron separados de sus cátedras el 51,43 por ciento de los profesores, en el Instituto de Santiago de Cuba el 63,16 por ciento eran infidentes y fueron separados de sus cátedras, en el Instituto de Matanzas lo fueron el 71,43 por ciento y en el Instituto de Puerto Príncipe el 88,24 por ciento. Los institutos de la zona oriental se vieron más afectados por la represión política de las autoridades de la isla a la vista del porcentaje de infidentes en los mismos.

En el Instituto de La Habana el porcentaje de doctores era del 40 por ciento, porque muchos de ellos habían sido catedráticos en la universidad de La Habana antes de separarse la segunda enseñanza de la universidad en 1863, en este instituto el porcentaje de insurrectos es del 51,43 por ciento. En los institutos de Santiago de Cuba, Matanzas y Puerto Príncipe, donde el porcentaje de rebeldes es mayor, es menor el porcentaje de doctores, con 15,79 por ciento, 14,29 por ciento y 5,88 por ciento respectivamente.

En los cuatro institutos predominaban los titulados en Derecho y en Medicina que representaban el 26,27 por ciento y 19,19 por ciento respectivamente. El porcentaje de criollos en el Instituto de La Habana era del 62,86 por ciento y los nacidos en España representaban el 31,43 por ciento. En el Instituto de Santiago de Cuba los criollos ascendían al 78,95 por ciento y los nacidos en España el 21,05 por ciento. En el Instituto de Matanzas los criollos eran el 75 por ciento y los nacidos en España el 17,86 por ciento. Finalmente, en el Instituto de Puerto Príncipe los criollos representaban el 82,35 por ciento y los nacidos en España el 17,65 por ciento. Podemos observar que donde es mayor el porcentaje de criollos también es mayor el porcentaje de insurrectos.

Como consecuencia de la depuración de los profesores y la supresión en 1871 de los institutos de Matanzas, Puerto Príncipe y Santiago de Cuba, y para solucionar el problema de los profesores que fueron destituidos, el Gobierno General Político tuvo que autorizar a numerosos individuos para poder dar lecciones de segunda enseñanza en los 43 centros privados incorporados al instituto provincial de segunda enseñanza de La Habana. En esos centros también se produjeron frecuentes alteraciones en el cuadro de profesores, lo que nos lleva a sospechar que, probablemente, al igual que ocurrió en SHJ, 2022, 2(I), pp. 46-68. ISSN: 2792-3967 
los institutos públicos, muchos de ellos fueron separados de sus puestos por motivaciones políticas. A partir de la paz de Zanjón se produjeron indultos, y en muy pocos casos algunos catedráticos acusados de delitos de infidencia volvieron a dar clases a partir de 1882, cuando se vuelven abrir los tres institutos suprimidos -Matanzas, Puerto Príncipe y Santiago de Cuba- y se crean los Institutos de Pinar del Río y Santa Clara.

La guerra de 1895-1898 levantó de nuevo las suspicacias del Gobernador General hacia los Catedráticos. Las autoridades de la isla temían al colectivo y algunos hechos aislados confirmaron sus temores. Así, en junio de 1895 se acusó al catedrático Leandro González Alcorta, Catedrático de Psicología, Lógica y Ética y Retórica y Poética, del Instituto de Segunda Enseñanza de Pinar del Río de infundir en sus discípulos ideas perniciosas. Con la política represiva de Valeriano Weyler, que imitaba a la de Valmaseda, se ordenó que se suspendiera la matrícula para el curso 1896-1897 en los Institutos de Segunda Enseñanza de Pinar del Río, Puerto Príncipe y Santa Clara por cuestiones similares a la Guerra de los Diez Años, motivos políticos, también había catedráticos que conspiraron contra el Gobierno y difundieron doctrinas contrarias a la integridad de la nación. A partir de entonces los colegios privados incorporados al instituto de Pinar del Río quedaban incorporados al instituto de La Habana y los de Puerto Príncipe y Santa Clara quedaban incorporados al instituto de Matanzas. En algunos documentos también se indica que se suprimieron las clases en el instituto de Santiago de Cuba y el de La Habana perdió gran cantidad de alumnos y profesores. También sufrieron las consecuencias de la guerra las escuelas preparatorias, las escuelas normales y las de artes y oficios. Igual que sucedió en 1871, de nuevo se aducían motivos económicos y de matrícula para la supresión de los institutos, pero si comparamos los datos de matrícula del curso 1893/94 de los institutos suprimidos (Pinar del Río, Santa Clara y Puerto Príncipe) con los de la península, vemos que, en los institutos de Palencia, Soria, Segovia, Ávila, Cuenca, Ciudad Real, Huelva, Logroño, Teruel, Baeza, Cabra, Figueras, Gijón, Reus, Tapia y Mahón, que tenían menor número de alumnos que los institutos suprimidos en Cuba, se puede deducir que aparte de las cuestiones económicas, también había motivaciones políticas en dicha supresión.

\section{| Conclusiones |}

En el presente trabajo aportamos, desde el ámbito de la política educativa de segunda enseñanza, algunos elementos para el estudio de la política colonial española en la isla de Cuba en la segunda mitad del siglo XIX. En el Archivo Nacional de Cuba pude analizar, de primera mano, valiosos expedientes que han confirmado mi principal hipótesis de partida: el relevante protagonismo de los catedráticos de instituto en el proceso independentista cubano, lo que nos ha permitido realizar un progreso sobre el estado actual de conocimiento histórico. El número total de catedráticos en los cuatro institutos de la isla en la etapa de la guerra Grande (1868-1878) fue de 99, de los cuales 65 (es decir el 65,66 por ciento) fueron acusados de delitos de infidencia, separados de sus cátedras y algunos ejecutados por motivos políticos. 
A partir de 1868 muchos catedráticos evolucionaron de posiciones autonomistas o asimilistas a posiciones claramente independentistas. El gobierno del conde de Valmaseda realizó en 1871 una serie de reformas que afectaban a los estudios y a los profesores tanto de institutos como de la Universidad de La Habana y suprimía, asimismo por cuestiones políticas, los institutos de Segunda Enseñanza y de Aplicación establecidos en Matanzas, Puerto Príncipe y Santiago de Cuba. También reorganizaba el Instituto de La Habana y depuraba al profesorado, siendo clausurados los colegios privados cuyos directores eran desafectos a España y cesando y sustituyendo muchos profesores por otros. Muchos de los Catedráticos de la Universidad de La Habana huyeron al extranjero al estallar la insurrección de 1868 "para continuar allí su obra de conspiración" (según los archivos analizados). Esa docencia fue asumida por profesores auxiliares.

El independentismo de los catedráticos de instituto está directamente relacionado con la evolución de la política educativa en la colonia. Las autoridades metropolitanas ponían en cuestión la labor del profesorado en los institutos públicos y se sancionaba a los catedráticos por motivos políticos. La represión y las sanciones influyeron igualmente en la construcción y deconstrucción de las narrativas identitarias de los catedráticos antillanos. Las cifras de catedráticos infidentes nos indican que, efectivamente, los institutos eran espacios de sociabilidad insurreccional donde se difundieron ideas independentistas y los catedráticos conformaban verdaderas células de conspiración y oposición política a las autoridades de la metrópoli. De ahí la supresión de los institutos, la depuración de los libros de texto y la depuración del profesorado.

Consideramos que la realización de futuras investigaciones acerca de los profesores de los colegios privados de segunda enseñanza y también de los maestros y de los catedráticos de la Universidad de La Habana en la etapa de la Guerra Grande contribuiría de manera muy notable a completar el conocimiento del protagonismo de los profesores en el proceso independentista de Cuba en el siglo XIX.

\section{Referencias}

Alonso Romero, M. P. (2002). Cuba en la España liberal (1837-1898): Génesis y desarrollo del régimen autonómico. Centro de Estudios Políticos y Constitucionales.

Agüero y Sánchez, P. (1867). Historia de la instrucción pública en la isla de Cuba. Imprenta El Iris.

Bachiller y Morales, A. (1859). Apuntes para la historia de las letras y de la instrucción pública de la isla de Cuba. Imprenta de P. Massana.

Bachiller y Morales, A. (1869). Documento manuscrito e informe de Antonio Bachiller y Morales según acuerdo de la reunión secreta celebrada el día 13 de enero de 1869 en casa del Marqués de Campo Florido en La Habana. BNJM

Barcia, M. C. (1987). Burguesía esclavista y abolición. Editorial de Ciencias Sociales.

Burke, P. (1980). Sociology and history. Allen \& Unwin.

SHJ, 2022, 2(I), pp. 46-68. ISSN: 2792-3967

65 
Cabrera Rodríguez, F. (1890). Educación de sordomudos. El Magisterio, 5(33, 34) PP. $265-266$ y 355.

Cabrera, O, e Ibarra Cabrera, I. (2010). Cuba: Perspectiva histórica de la formación de maestros en Cuba. Revista Complutense de Educación, 21(1), pp. 37-51.

Cañizares Márquez, J. A. (2018). La rebelión de los Catedráticos de Instituto en Cuba (1868-1878). Espacio, Tiempo y Forma (Serie V. Historia Contemporánea), 30, pp. 55-95.

Carnoy, M. (1995). La educación como imperialismo cultural. Siglo XXI.

Jorrín, J. S. (1886, octubre). La educación física en Cuba. Revista Cubana.

Juliá, S (1989). Historia social/Sociología histórica. Siglo XXI.

Lario, Á. (2017). Cuba y la Monarquía Constitucional. En J. Alvarado Planas (Coord.) La Administración de Cuba en los siglos XVIII y XIX. Boletín Oficial del Estado y Centro de Estudios Políticos y Constitucionales, Pp. 243-276

Leal Spengler, E. (1988). La Habana. Ciudad antigua. Editorial Letras Cubanas.

Leiva Luna, E. (1944). “La Empresa”, el colegio con alma cubana. Matanzas.

Le Roy y Gálvez, L. F. (1971). A cien años del 71. El fusilamiento de los estudiantes, Editorial de Ciencias Sociales.

Liras, J. E. (1894). La primera enseñanza en la isla de Cuba. Historia de las escuelas municipales y demás establecimientos de enseñanza. Imprenta de Elías Fernando.

López Segrera, F (1982). Sociología de la colonia y neocolonia cubana (1510-1959). Editorial de Ciencias Sociales.

Mann, M. (1986). The sources of social power, Cambridge University Press.

Opatrný, J. (1986). Antecedentes históricos de la formación de la nación cubana. IberoAmericana Pragensia,

Pupo, R. (2005). Identidad, Emancipación y Nación Cubana. Editora Política.

Rodríguez, J. I. (1900). Estudio histórico sobre el origen, desenvolvimiento y manifestaciones prácticas de la idea de la anexión de la isla de Cuba a los Estados Unidos de América. Imprenta La Propaganda Literaria.

Rubio, J. (1995). La cuestión de Cuba y las relaciones con los Estados Unidos durante el reinado de Alfonso XII. Biblioteca Diplomática Española, Ministerio de Asuntos Exteriores.

Rubio, J. (2004). El final de la era de Cánovas. Los preliminares del "desastre" de 1898. Ministerio de Asuntos Exteriores.

Sedano y Cruzat, C. (1872). Cuba. Estudios Políticos, Imprenta a cargo de Manuel G. Hernández.

Sosa Rodríguez, E. y A. Penabad Félix (2010). Historia de la Educación en Cuba, tomo 9. Pueblo y Educación. 
Stucki, A. (2017). Las guerras de Cuba, violencia y campos de concentración (1868-1898). La Esfera de los Libros.

Valdés Domínguez, F. (1969). El 27 de noviembre de 1871. Universidad de La Habana.

Varona, E. J. (1901). La Instrucción Pública en Cuba. Imprenta de Rambla y Bouza.

Vázquez Pérez, M. (2012). Antonio Bachiller y Morales. Edición crítica. Textos de José Martí referentes a Antonio Bachiller y Morales. Centro de Estudios Martianos.

Weber, M. (1921/1993). Economía y Sociedad. Fondo de Cultura Económica.

\section{Anexos}

Tabla 1. Catedráticos de Institutos de Segunda Enseñanza en Cuba (1868-1878).

\begin{tabular}{ccccccc}
\hline \multicolumn{6}{c}{ Catedráticos de Institutos de Segunda Enseñanza en Cuba (1868-1878) } \\
$\begin{array}{c}\text { Instituto } \\
\text { de Segunda } \\
\text { Enseñanza }\end{array}$ & $\begin{array}{c}\text { Número de } \\
\text { Catedráticos } \\
1868-1878\end{array}$ & $\begin{array}{c}\text { Nacidos } \\
\text { en } \\
\text { América }\end{array}$ & $\begin{array}{c}\text { Nacidos en } \\
\text { España }\end{array}$ & $\begin{array}{c}\text { Origen } \\
\text { Desconocido }\end{array}$ & $\begin{array}{c}\text { Número de } \\
\text { Infidentes } \\
1868-1878\end{array}$ & $\begin{array}{c}\text { Porcentaje } \\
\text { de Infidentes } \\
1868-1878\end{array}$ \\
\hline La Habana & 35 & $62,86 \%$ & $31,43 \%$ & $5,71 \%$ & 18 & $51,43 \%$ \\
\hline $\begin{array}{c}\text { Santiago } \\
\text { de Cuba }\end{array}$ & 19 & $78,95 \%$ & $21,05 \%$ & - & 12 & $63,16 \%$ \\
\hline $\begin{array}{c}\text { Matanzas } \\
\text { Príncipe }\end{array}$ & 28 & $75,00 \%$ & $17,86 \%$ & $7,14 \%$ & 20 & $71,43 \%$ \\
\hline $\begin{array}{c}\text { Puerto } \\
\text { Total }\end{array}$ & 17 & $82,35 \%$ & $17,65 \%$ & - & 15 & $88,24 \%$ \\
\hline
\end{tabular}

Fuente: Elaboración propia a partir de los archivos consultados

\section{Nota biográfica}

José Antonio Cañizares Márquez es doctor en Historia por la UNED, licenciado en Ciencias Políticas y Sociología (sección Ciencia Política y de la Administración y sección Sociología) por la Universidad Complutense de Madrid, licenciado en Historia (UNED) y licenciado en Antropología Social y Cultural (UNED). También realizó los estudios de doctorado en Estructura Social y Sociología de la Educación en la Universidad Complutense. 
Funcionario de carrera del Cuerpo de Profesores de Enseñanza Secundaria en la especialidad de Geografía e Historia, ha sido profesor asociado de Ciencia Política en la Universidad Carlos III de Madrid. Desde 2014 es profesor asociado en el Departamento de Historia, Teorías y Geografía Políticas de la Universidad Complutense, además es profesor tutor en la UNED.

$\mathrm{Ha}$ sido investigador invitado en el Instituto de Historia de Cuba. Sus líneas de investigación están relacionadas con la geopolítica y estudio de la política colonial en Cuba en el siglo XIX. 